\title{
Correlation of the Oncoplastic Excision Volumes with the Aesthetic Outcomes for the Upper Outer Quadrant Breast Cancer
}

\author{
MOHAMED IBRAHIM, M.D. and MOHAMED FARAG, M.D. \\ The Department of General Surgery, Faculty of Medicine, Fayoum University
}

\begin{abstract}
Background: Oncoplastic breast surgery (OBS) has emerged as more advanced surgical approaches which combine the principles of both the oncological and plastic surgeries to achieve those advanced results and to expand the tumour size indication in front of the conservative management.

Methods: From July 2016 to March 2019, 200 patients presented with UOQ primary breast cancer including multifocal and post neoadjuvant cases with predicted excision volume (PEV) less than 35\% were operated and enrolled in this prospective study. Aesthetic outcomes were objectively evaluated 6 months after surgery by the semi-automated Breast Cancer Conservative Treatment (BCCT) core software.

Results: Total aesthetic results according to the objective BCCT core assessment were excellent in $41.5 \%$ (83 cases), good in $29.5 \%$ (59 cases), fair in $19.5 \%$ (39 cases), and poor in $9.5 \%$ (19 cases). More than $90 \%$ of the patients with EEV less than $10 \%$ have achieved excellent aesthetic results; EEV from 10 to $15 \%$ has achieved more than $60 \%$ good results; EEV from 15 to $20 \%$ has achieved around $50 \%$ fair results which have been approached the $70 \%$ in the 20 to $25 \%$ group; more than $40 \%$ poor results were noticed in the 25 to $30 \%$ EEV which were raised up to $75 \%$ in the 30 to $35 \% \mathrm{EEV}$.

Conclusion: Excision volume ratio has become one of the main determinants of the aesthetic results; its preoperative value can refer to the most suitable oncoplastic surgical technique for each patient, expect the forthcoming discrepancy and the necessity for contralateral symmetrization. Current study has revealed the necessity of discrepancy corrective surgery or performing volume replacement reconstruction with the EEV more than $20 \%$ in the UOQ and from 15 to $20 \%$ in the fair results according to the patients' preference.
\end{abstract}

Key Words: Aesthetic outcomes - Oncoplastic surgery Excision volumes - Upper outer quadrant-Breast cancer.

\section{INTRODUCTION}

Breast conserving surgery (BCS) has become the main surgical approach combined with radiotherapy for management of early breast cancer; statistical results has confirmed the same survival and local recurrence rates as modified radical mastectomy with an eminent advance in the aesthetic outcome, psychological impact and quality of life [1-4].

Although this fact has a wide assent making the BCS the standard surgical management for the early breast cancer with a wide consensus on the safety of the oncological outcomes, there is still a growing race in the modern breast surgery to achieve more advanced and natural aesthetic results; this race has motivated the appearance of the oncoplastic breast surgery (OBS) as more advanced surgical approaches which combine the principles of both the oncological and plastic surgeries [5-9].

OBS has rapidly expanded to include many different surgical techniques classified into the volume displacement and replacement; it has gained wide popularity in many countries around the world with noticed flared rate of the annual performed procedures [10-12].

Traditionally, classic BCS was reserved for patients with tumor size of $5 \mathrm{~cm}$ or less to permit a safe oncological resection with an acceptable aesthetic outcome; however, the emergence of the more important item of the tumour size ratio relative to the breast size and the continual advances in the neo-adjuvant regimens have expanded tumour size indication in front of the conservative management [13-15].

Many studies have revealed that up to $25-30 \%$ of the classic BCS procedures may result in poor aesthetic outcomes and have regarded those unacceptable results to the excision of more than 10$20 \%$ of the breast volume depending on the site of the tumour [16,17]; OBS has enabled breast surgeons to excise larger volumes from the breast and expanded those excision ratios for larger tumours excision (small breast - tumour ratio) with preser- 
vation of good aesthetic outcomes [10,18-20]; however, the question which has been raised is "what are the correlation of those expanded excision volumes with the aesthetic outcomes for each breast quadrant?"

As the upper outer quadrant (UOQ) of the breast has been statistically established as the most common site for the development of the breast cancer and possesses most of the distributed breast tissue $[\mathbf{2 1 , 2 2}]$; we have decided to find an answer of the former question for this quadrant.

\section{PATIENTS AND METHODS}

From July 2016 to March 2019, 200 patients presented with UOQ primary breast cancer including multifocal and post neoadjuvant cases with predicted excision volume (PEV) less than 35\% and fulfilling the other eligibility criteria of the breast conservative therapy; were evaluated, consented, operated and enrolled in this prospective study. Preoperative determination of the PEV was done for all the patients from this mathematical equation introduced by Cochrane et al. [23]:

$$
\mathrm{PEV}=\frac{4(\text { Radius of Lesion }+1 \mathrm{~cm})^{3}}{(\text { Radius of Breast })^{2} \times \text { Height of Breast }}
$$

Breast volume (BV) was calculated as an elliptical cone based on the preoperative medio-lateral oblique (MLO) mammogramic view using this formula $[23,24]$ :

$$
\mathrm{BV}=1 / 3 \pi \text { breast radius } 2 \times \text { Breast height. }
$$

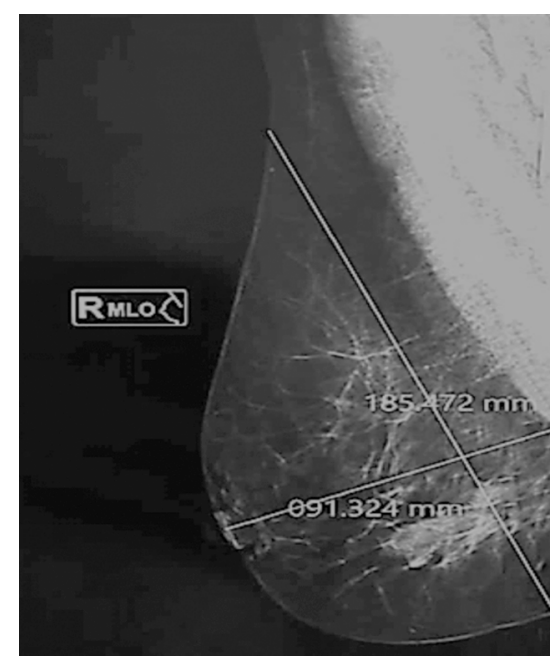

Fig. (1): MLO mammogramic view showing the estimated breast radius and height.

Specimen volumes were measured after surgical excision by Archimedes (Water Displacement) method [25].
The estimated excision volume (EEV) was calculated by dividing the measured specimen volume (Archimedes method) by the calculated $\mathrm{BV}$ from the MLO mammogramic view.

We have adopted two different volume displacement oncoplastic surgical techniques for our patients in this study including the round block technique for those who presented with small to medium sized breasts without major ptosis and have tumour within the $5 \mathrm{~cm}$ periareolar area in the UOQ without nipple invasion and with no need for excision of the overlying skin. The other adopted technique was the racquet incision which was indicated for the patients presented with medium to large sized breasts without major ptosis and have tumour located outside the $5 \mathrm{~cm}$ periareolar area in the UOQ, or in a need for excision of the overlying skin to achieve adequate safety margin. All tumours were excised with palpable safety margins of $1 \mathrm{~cm}$. Aesthetic outcomes were objectively evaluated 6 months after surgery and after adjuvant radiotherapy.

This evaluation was done by the semi-automated Breast Cancer Conservative Treatment (BCCT) core software presented by Cordoso et al. [26] using frontal two-dimensions digital photos that were taken by a single photographer using 12 megapixel digital camera; both flash use and asymmetric illumination were avoided using single light source standing at equal distances from both breasts with the use of a light coloured non-reflective background behind. Patients were stood at attention with their hands on their hips (standardized view). Our photographic framing was made to include the suprasternal notch above and the scale mark below (midline drawn point $25 \mathrm{~cm}$ inferior to the suprasternal notch); this determined frame has controlled and standardized the distance between camera and patients, and maintained constant picture magnification.

Each photo was loaded on the BCCT. Core 3.0 software $\AA$ and the digital red dots were adjusted manually on the suprasternal notch, scale mark, nipples and axillae on both sides and the "Auto Adjust" button was pressed. Software automatically identifies the breast contour on both sides and adjusts the white digital dots over them and carries out automated measurements to calculate the overall aesthetic outcomes in the 4-point scale.

\section{RESULTS}

In this study, patients' age has ranged from 28 to 64 years old (mean $42.7 \pm 9.4$ years), breast volume from 476 to $1170 \mathrm{cc}$ (mean $836.5 \pm 184.2 \mathrm{cc}$ ), 
specimen volume from 76 to $290 \mathrm{cc}$ (mean $150.3 \pm$ $47.5 \mathrm{cc}$ ), PEV from 6 to $32.7 \%$ (mean $16.03 \% \pm$ $3.72 \%$ ), and EEV from 7.5 to $34.5 \%$ (mean $18.29 \%$ $\pm 4.84 \%$ ); total aesthetic results according to the objective BCCT core assessment were excellent in $41.5 \%$ ( 83 cases), good in $29.5 \%$ (59 cases), fair in $19.5 \%$ (39 cases), and poor in $9.5 \%$ (19 cases).

Patients were divided into six groups according to the percentage of excision volume and the objective BCCT core aesthetic results were analyzed for each group (Table 1).

More than $90 \%$ of the patients with EEV less than $10 \%$ have achieved excellent aesthetic results;
EEV from 10 to $15 \%$ has achieved more than $60 \%$ good results; EEV from 15 to $20 \%$ has achieved around $50 \%$ fair results which have been approached the $70 \%$ in the 20 to $25 \%$ group; more than $40 \%$ poor results were noticed in the 25 to $30 \% \mathrm{EEV}$ which were raised up to $75 \%$ in the 30 to $35 \% \mathrm{EEV}$.

Round block oncoplastic surgical technique was indicated for 123 patients and racquet incision for 77 patients. About $80 \%$ of the round block patients and $55 \%$ of the racquet incision patients have achieved acceptable (excellent and good) results.

Table (1): EEV groups and the BCCT core aesthetic results.

\begin{tabular}{lccccc}
\hline EEV & Excellent & Good & Fair & Poor & Total \\
\hline Up to $10 \%$ & $56(92 \%)$ & $5(8 \%)$ & - & - & $61(30.5 \%)$ \\
10 to $15 \%$ & $24(37 \%)$ & $41(63 \%)$ & - & - & $65(32.5 \%)$ \\
15 to $20 \%$ & $3(10 \%)$ & $11(38 \%)$ & $15(52 \%)$ & - & $29(14.5 \%)$ \\
20 to $25 \%$ & - & $2(10.5 \%)$ & $13(68.5 \%)$ & $4(21 \%)$ & $19(9.5 \%)$ \\
25 to $30 \%$ & - & - & $8(57 \%)$ & $6(43 \%)$ & $14(7 \%)$ \\
30 to $35 \%$ & - & - & $3(25 \%)$ & $9(75 \%)$ & $12(6 \%)$ \\
\hline Total & $83(41.5 \%)$ & $59(29.5 \%)$ & $39(19.5 \%)$ & $19(9.5 \%)$ & 200 \\
\hline
\end{tabular}

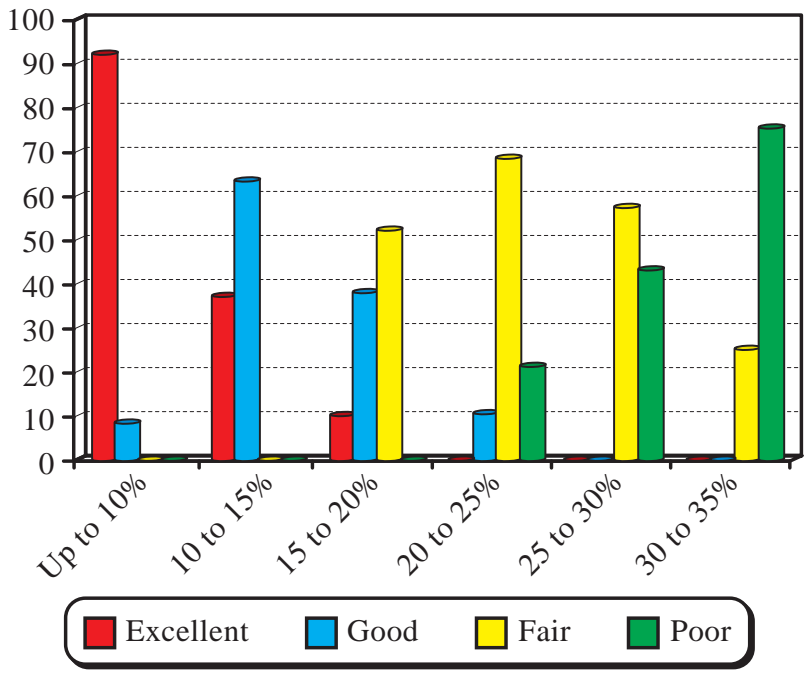

Chart (1): EEV groups and the BCCT core aesthetic results.

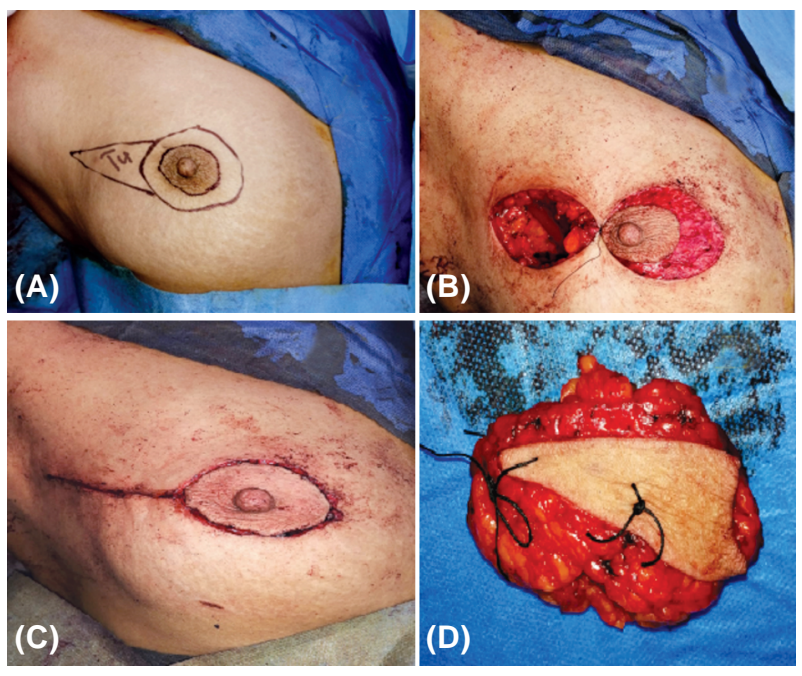

Fig. (2): On table photo (A): Tumour location, (B): After excision, (C): After reconstruction by round block technique, (D): Operative specimen. 


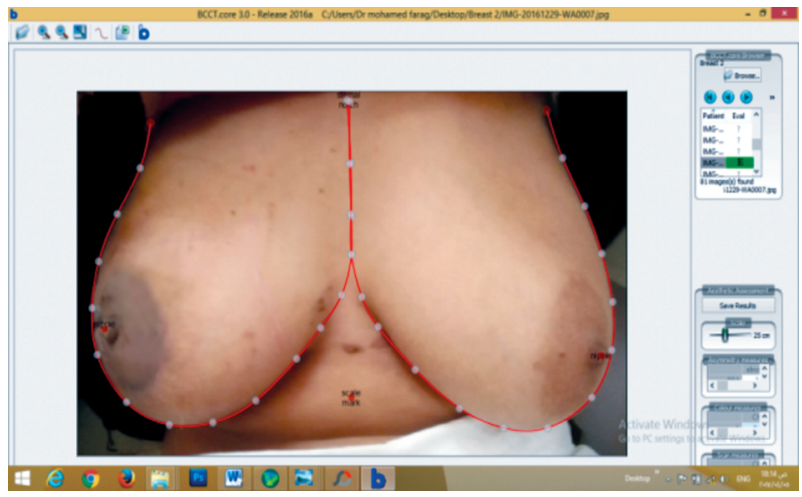

Fig. (3): Right side round block and excellent BCCT core result.

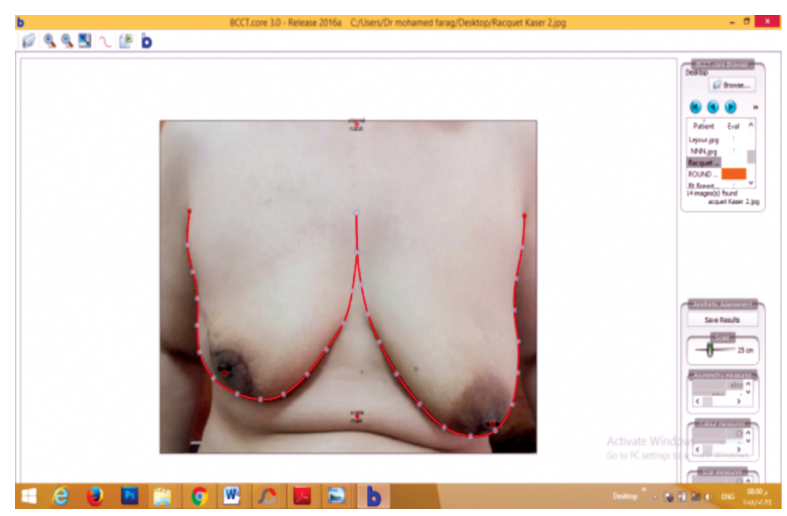

Fig. (5): Right side racquet incision and fair BCCT core result.

\section{DISCUSSION}

In the modern breast surgery, excision volume ratio has replaced the classic indication of the tumour size for breast conservation $(5 \mathrm{~cm}$ or less) and become one of the main determinants of the aesthetic outcome [27]; this ratio can be calculated prospectively to expect this outcome, determine the most suitable oncoplastic surgical technique for each patient and the need for contralateral symmetrization to augment the aesthetic results $[23,28,29]$.

Our study has been designed to correlate the excision volumes of the volume displacement oncoplastic techniques for the UOQ breast cancer with the aesthetic outcomes before the contralateral symmetrization.

After review of the literature, Cochrane et al. [23] equation that have been proposed for calculating the PEV was adopted in this study, Archimedes' method [25] was adopted as a direct, easy and accurate method for evaluation of the specimens' volumes, and the proposed formulae that treats the breast as a cone depending on the dimensions

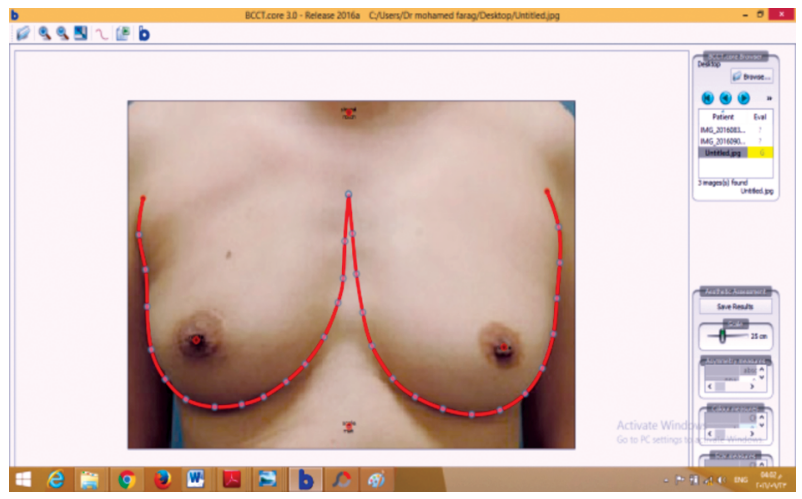

Fig. (4): Right side round block and good BCCT core result.

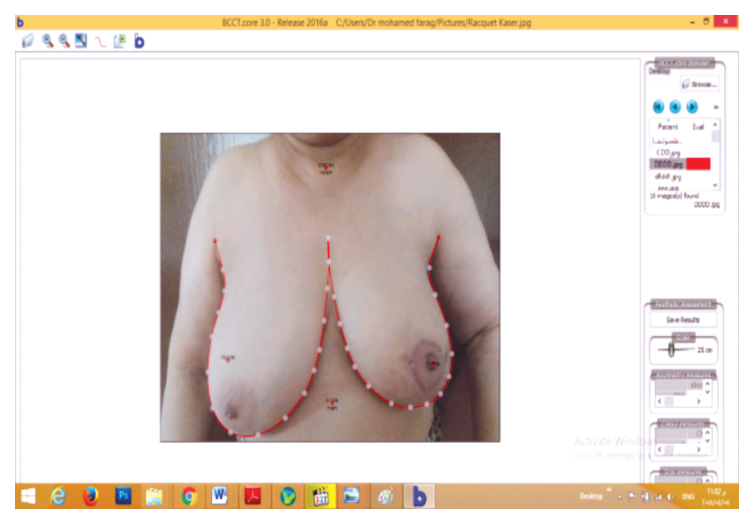

Fig. (6): Left side racquet incision and poor BCCT core result.

measured from the oblique mammogramic film rather than the craniocaudal one was accepted as an accurate and readily available method for measurement of the breast volume [30].

Many different methods for the postoperative aesthetic assessment have been mentioned in literature; some depend on the patient's self-evaluation or the observer evaluation representing the subjective methods and others depend on the physical and the photographic measurements to represent the objective methods [31-35]; we have intended to depend on the objective method (BCCT core software) [26] to review our results excluding the possibility of subjective bias.

In the current study, total aesthetic results according to the objective BCCT core assessment were excellent in $41.5 \%$ ( 83 cases), good in $29.5 \%$ (59 cases), fair in $19.5 \%$ (39 cases), and poor in 9.5\% (19 cases); those results were in close correspondence with the results of the systematic review (36) that has included 25 studies evaluating the aesthetic outcomes of the OBS for breast cancer patients $(n=1,962)$ and revealed excellent, good, 
fair and poor outcomes in $55.2 \%, 31.0 \%, 9.4 \%$ and $4.4 \%$ of the patients respectively.

According to the aesthetic results of the current study for each EEV group, EEV up to $10 \%$ from the UOQ of the breast gives $90 \%$ excellent results and those patients are not in a need for contralateral symmetrization as the produced discrepancy has a little effect on the aesthetic outcome.

EEV from 10 to $15 \%$ gives excellent and good results at rates of about $40 \%$ and $60 \%$ respectively and those results are also in no need for discrepancy correction.

EEV from 15 to $20 \%$ has given acceptable results (excellent in 10\%, good in about $40 \%$, and fair in about 50\%); however, fair results in this group still can be improved by the discrepancy corrective procedures taking into consideration the patients' preference.

Most of the patients with EEV more than 20\% have achieved unacceptable aesthetic results which should be improved by the contralateral symmetrization or by performing the surgical excision with replacement reconstruction instead of the displacement techniques.

Many previous studies [37-41] have suggested that excision of more than $20 \%$ of the breast volume has a clear risk of deformity, unacceptable aesthetic results, psychological morbidity, and contralateral symmetrization or volume replacement surgery should be considered for this excision ratio.

\section{Conclusion:}

Over the last two decades, the aesthetic deformities that have faced both patients and surgeons after standard BCS have motivated the appearance of OBS which has enabled breast surgeons to excise larger volumes and achieve advanced aesthetic outcomes. Excision volume ratio has become one of the main determinants of those aesthetic results; its preoperative value can refer to the most suitable oncoplastic surgical technique for each patient, expect the forthcoming discrepancy and the necessity for contralateral symmetrization to augment the aesthetic results. Current study has revealed the necessity of discrepancy corrective surgery or performing the surgical excision with volume replacement reconstruction instead of the displacement techniques with the EEV more than $20 \%$ in the UOQ and from 15 to $20 \%$ in the fair results according to the patients' preference.

\section{REFERENCES}

1- Fisher B., Anderson S., Bryant J., Margolese R., Deutsch M., Fisher E., Jeong J. and Wolmark N.: Twenty-Year Follow-up of a Randomized Trial Comparing Total Mastectomy, Lumpectomy, and Lumpectomy plus Irradiation for the Treatment of Invasive Breast Cancer. New England Journal of Medicine, 347 (16): pp. 1233-1241, 2002.

2- Kronowitz S., Feledy J., Hunt K., Kuerer H., Youssef A., Koutz C. and Robb G.: Determining the Optimal Approach to Breast Reconstruction after Partial Mastectomy. Plastic and Reconstructive Surgery, 118 (3): pp. 814-815, 2006.

3- Struikmans H., Bartelink H., Horiot J., Poortmans P., Van den Bogaert W., Fourquet A., Jager J., Hoogenraad W., Bing Oei S., Wárlám-Rodenhuis C., Pierart M. and Collette L.: Impact of a higher radiation dose on local control and survival in breast-conserving therapy of early breast cancer: 10-year results of the Randomized Boost Versus No Boost. European Journal of Cancer Supplements, 25 (22): pp. 3259-3265, 2007.

4- Pukancsik D., Kelemen P., Újhelyi M., Kovács E., Udvarhelyi N., Mészáros N., Kenessey I., Kovács T., Kásler M. and Mátrai Z.: Objective decision making between conventional and oncoplastic breast-conserving surgery or mastectomy: An aesthetic and functional prospective cohort study. European Journal of Surgical Oncology, 43 (2): pp. 303-310, 2017.

5- Santos G., Urban C., Edelweiss M., Zucca-Matthes G., de Oliveira V., Arana G., Iera M., Rietjens M., de Lima R., Spautz C., Kuroda F., Anselmi K. and Capp E.: LongTerm Comparison of Aesthetical Outcomes After Oncoplastic Surgery and Lumpectomy in Breast Cancer Patients. Annals of Surgical Oncology, 22 (8): pp. 2500-2508, 2014.

6- Heil J., Czink E., Golatta M., Schott S., Hof H., Jenetzky E., Blumenstein M., Maleika A., Rauch G. and Sohn C.: Change of aesthetic and functional outcome over time and their relationship to quality of life after breast conserving therapy. European Journal of Surgical Oncology, 37 (2): pp. 116-121, 2011.

7- De Lorenzi F., Loschi P., Bagnardi V., Rotmensz N., Hubner G., Mazzarol G., Orecchia R., Galimberti V., Veronesi P., Colleoni M., Toesca A., Peradze N. and Mario R.: Oncoplastic Breast-Conserving Surgery for Tumors Larger than 2 Centimeters: Is it Oncologically Safe? A Matched-Cohort Analysis. Annals of Surgical Oncology, 23 (6): pp. 1852-1859, 2016.

8- Wijgman D., ten Wolde B., van Groesen N., KeemersGels M., van den Wildenberg F. and Strobbe L.: Short term safety of oncoplastic breast conserving surgery for larger tumors. European Journal of Surgical Oncology, 43 (4): pp. 665-671, 2017.

9- Ojala K., Meretoja T. and Leidenius M.: Aesthetic and functional outcome after breast conserving surgery Comparison between conventional and oncoplastic resection. European Journal of Surgical Oncology, 43 (4): pp. 658-664, 2017.

10- Malycha P., Gough I., Margaritoni M., Deo S., Sandelin K., Buccimazza I. and Agarwal G.: Oncoplastic Breast Surgery: A Global Perspective on Practice, Availability, 
and Training. World Journal of Surgery, 32 (12): pp. 25702577,2008

11- Pires D., Junior O., Valadares C. and Andrade R.: Training in oncoplastic and reconstructive breast surgery: Analysis of training in America and in the European Union with the brazilian reality. Revista Brasileira de Mastologia, 27 (2): pp. 164-171, 2017.

12- Campbell E. and Romics L.: Oncological safety and cosmetic outcomes in oncoplastic breast conservation surgery, a review of the best level of evidence literature. Breast Cancer: Targets and Therapy, 9: pp. 521-530, 2017.

13- Singletary S.: Surgical margins in patients with earlystage breast cancer treated with breast conservation therapy. The American Journal of Surgery, 184 (5): pp. 383393, 2002.

14- Masetti R., Di Leone A., Franceschini G., Magno S., Terribile D., Fabbri M. and Chiesa F.: Oncoplastic Techniques in the Conservative Surgical Treatment of Breast Cancer: An Overview. The Breast Journal, 12 (s2): pp. S174-S180, 2006.

15- Emiroglu M., Sert I. and Inal A.: The Role of Oncoplastic Breast Surgery in Breast Cancer Treatment. The Journal of Breast Health, 11 (1): pp. 1-9, 2015.

16- Lanitis S. and Hadjiminas D.: Oncoplastic surgery: Taking breast surgery to the next level. Hellenic Journal of Surgery, 84 (2): pp. 92-105, 2012.

17- Dahlbäck C., Manjer J., Rehn M. and Ringberg A.: Determinants for patient satisfaction regarding aesthetic outcome and skin sensitivity after breast-conserving surgery. World Journal of Surgical Oncology, 14 (1): pp. 17-28, 2016.

18- Dos Santos G. and Urban C.: Aesthetics and Quality of Life after Breast Reconstruction. In: C. Urban and M. Rietjens, ed., Oncoplastic and Reconstructive Breast Surgery, $1^{\text {st }}$ ed. Milan: Springer-Verlag, pp. 431-440, 2013.

19- Down S., Jha P., Burger A. and Hussien M.: Oncological Advantages of Oncoplastic Breast-Conserving Surgery in Treatment of Early Breast Cancer. The Breast Journal, 19 (1), pp. 56-63, 2013.

20- Noguchi M., Yokoi-Noguchi M., Ohno Y., Morioka E., Nakano Y., Kosaka T. and Kurita T.: Oncoplastic breast conserving surgery: Volume replacement vs. volume displacement. European Journal of Surgical Oncology, 42 (7): pp. 926-934, 2016.

21- Lee A.: Why is carcinoma of the breast more frequent in the upper outer quadrant? A case series based on needle core biopsy diagnoses. The Breast, 14 (2): pp. 151-152, 2005.

22- Rummel S., Hueman M., Costantino N., Shriver C. and Ellsworth R.: Tumour location within the breast: Does tumour site have prognostic ability?. Ecancer Medical Science, 9 (552): pp. 1-10, 2015.

23- Cochrane R., Valasiadou P., Wilson A., Al-Ghazal S. and Macmillan R.: Cosmesis and satisfaction after breastconserving surgery correlates with the percentage of breast volume excised. British Journal of Surgery, 90 (12): pp. 1505-1509, 2003.

24- Chan S., Chueng P. and Lam S.: Cosmetic Outcome and Percentage of Breast Volume Excision in Oncoplastic
Breast Conserving Surgery. World Journal of Surgery, 34 (7): pp. 1447-1452, 2009.

25- Kayar R., Civelek S., Cobanoglu M., Gungor O., Catal H. and Emiroglu M.: Five Methods of Breast Volume Measurement: A Comparative Study of Measurements of Specimen Volume in 30 Mastectomy Cases. Breast Cancer: Basic and Clinical Research, 5: pp. 43-52, 2011.

26- Cardoso J. and Cardoso M.: Towards an intelligent medical system for the aesthetic evaluation of breast cancer conservative treatment. Artificial Intelligence in Medicine, 40 (2): pp. 115-126, 2007.

27- White J., Achuthan R., Turton P. and Lansdown M.: Breast Conservation Surgery: State of the Art. International Journal of Breast Cancer, 20 (11): pp. 1-10, 2011.

28- Yang J., Bae S., Chung H., Cho B., Park H. and Jung J.: The Usefulness of Oncoplastic Volume Displacement Techniques in the Superiorly Located Breast Cancers for Korean Patients with Small to Moderate-Sized Breasts. Annals of Plastic Surgery, 67 (5): pp. 474-480, 2011.

29- Munhoz A., Montag E. and Gemperli R.: Oncoplastic breast surgery: Indications, techniques and perspectives. Gland surgery, 2 (3): pp. 143-157, 2013.

30- Kalbhen C., McGill J., Fendley P., Corrigan K. and Angelats J.: Mammographic determination of breast volume: Comparing different methods. American Journal of Roentgenology, 173 (6): pp. 1643-1649, 1999.

31- Kim M., Sbalchiero J., Reece G., Miller M., Beahm E. and Markey M.: Assessment of Breast Aesthetics. Plastic and Reconstructive Surgery, 121 (4): pp. 186e-194e, 2008.

32- Cardoso M., Cardoso J., Vrieling C., Macmillan D., Rainsbury D., Heil J., Hau E. and Keshtgar M.: Recommendations for the aesthetic evaluation of breast cancer conservative treatment. Breast Cancer Research and Treatment, 135 (3): pp. 629-637, 2012.

33- Haloua M., Krekel N., Jacobs G., Zonderhuis B., Bouman M., Buncamper M., Niessen F., Winters H., Terwee C., Meijer S. and van den Tol M.: Cosmetic Outcome Assessment following Breast-Conserving Therapy: A Comparison between BCCT.core Software and Panel Evaluation. International Journal of Breast Cancer, pp. 1-7, 2014.

34- Cardoso M., Oliveira H. and Cardoso J.: Assessing cosmetic results after breast conserving surgery. Journal of Surgical Oncology, 110 (1): pp. 37-44, 2014.

35- Yu T., Eom K., Jang N., Kim K., Koo T., Kwon J., Kim B., Kang E., Kim S., Kim J. and Kim I.: Objective Measurement of Cosmetic Outcomes of Breast Conserving Therapy Using BCCT.core. Cancer Research and Treatment, 48 (2): pp. 491-498, 2016.

36- Campbell E. and Romics L.: Oncological safety and cosmetic outcomes in oncoplastic breast conservation surgery, a review of the best level of evidence literature. Breast Cancer: Targets and Therapy, 9: pp. 521-530, 2017.

37- Bulstrode N. and Shrotria S.: Prediction of cosmetic outcome following conservative breast surgery using breast volume measurements. The Breast, 10 (2): pp. 124126, 2001.

38- Masetti R., Di Leone A., Franceschini G., Magno S., Terribile D., Fabbri M. and Chiesa F.: Oncoplastic Tech- 
niques in the Conservative Surgical Treatment of Breast Cancer: An Overview. The Breast Journal, 12 (s2): pp. S174-S180, 2006.

39- Chan S., Chueng P. and Lam S.: Cosmetic Outcome and Percentage of Breast Volume Excision in Oncoplastic Breast Conserving Surgery. World Journal of Surgery, 34 (7): pp. 1447-1452, 2009.
40- Ogawa T., Hanamura N., Yamashita M., Kimura H. and Kashikura Y.: Breast-Volume Displacement Using an Extended Glandular Flap for Small Dense Breasts. Plastic Surgery International, pp. 1-7, 2011.

41- Emiroglu M., Sert I. and Inal A.: The Role of Oncoplastic Breast Surgery in Breast Cancer Treatment. The Journal of Breast Health, 11 (1): pp. 1-9, 2015. 